\title{
Realization of A Knowledge-based Intelligent System for Power Dispatching Plan Management
}

\author{
Qi $\mathrm{Liu}^{1}$, Yaoyi $\mathrm{Xu}^{2,,}$, Peng Zhan ${ }^{1}$, Xin $\mathrm{Li}^{1}$ and Qike $\mathrm{Wu}^{1}$ \\ ${ }^{1}$ Power Dispatching and Controlling Centre, Guangzhou Power Supply Co., Ltd., Guangzhou 510620, China \\ ${ }^{2}$ School of Electrical Engineering, South China University of technology, Guangzhou 510640, China
}

\begin{abstract}
With the expanding of power grid scale in Chinese metropolis, the task intensity of power dispatchers increases rapidly in regulation of the power system operation structure and states to deal with everyday scheduled maintenance. In this paper, we propose a knowledge-based intelligent system developed to deal with daily management of the power dispatching plans. The system will analyse all the operation state changing tasks arranged for the next day and group the plans according to their association. It will automatically check the security of each power dispatching plan and generate the corresponding dispatchingorder tickets. The proposed system builds up power grid ontology knowledge and first-order logic rules and integrates techniques of knowledge reasoning, natural language understanding and network topology analysis. Application shows that it can effectively realize the day-ahead power dispatching plan management (PDPM) instead of the human dispatchers.
\end{abstract}

\section{Introduction}

With the arrival of the new wave of artificial intelligence (AI), the construction of intelligent system in power system is in sustained growth [1-6]. Power dispatching and controlling is one of the hot areas for AI application. One of the challenges is how to build up the knowledge system about power dispatching in the machine, so that the computer can carry out complicated power dispatching tasks with high accuracy and efficiency instead of human dispatchers.

At present, most of the developed systems can only deal with some modules of the task, such as the inference of the dispatching-order tickets [7] and the trend data generating for pre-dispatching [8]. Although the papers [9-11] propose the ideas of intelligent robot or new paradigm for power dispatching and controlling, they have no further discussion on their designs and implementation.

The power supply system of a city is usually in looped network structure, but operated in open-loop mode to control the short-circuit current. Therefore, the operation mode will be frequently changed along with the outage or maintenance of the lines or transformers. For fast developing metropolis in China, most of the daily workload in power dispatching center comes from the operation modes switch process, which is composed of complicated cross-checking series to ensure the safety of the system. Usually, staffs of the maintenance department submit the equipment maintenance application through the OMS (Outage Management System). Then, the technicians responsible for operation mode schedule and protection setting provide their opinions on the OMS too. Finally, on the day before the execution of the power dispatching plans, the dispatcher needs to check the plans and evaluate their feasibility according to the load-forecast results and the latest system operation states. For the plans that pass through the check, the dispatcher will formulate corresponding dispatching-order tickets for the next-day execution of the plan. The dispatching-order ticket is a description of the specific operation sequences for the plan. During the process, the dispatcher may also exchange opinions with the applicants and the plan-makers via OMS or telephone to inquire or confirm the relevant issues.

In this paper, we present an intelligent computer system (IS) for the power dispatching plan management (PDPM), which can take over the task of dispatcher to realize fully automated closed-loop processing of the dispatching plans. The framework and main modules of the IS are introduced in section 2. Designing of the knowledge system is presented in section 3. A case test results as well as the discussions are given in section 4 of the paper.

\section{Framework and main module designs of the IS}

\subsection{System physical structure}

The physical structure of the IS for PDPM is shown in Figure 1.

The task controlling center is in charge of the workflow optimization so that the system can deal with piles of plans in parallel processing. In the task controlling center, the message management module interacts with the OMS and EMS (energy management system) through message

\footnotetext{
* Corresponding author: xu_yaoyi@,foxmail.com
} 
queue. The task management module controls the items and sequence of tasks in the task lists.

The inference engine is activated by different functional modules for knowledge reasoning. For example, the dispatching-order ticket is generated by the rule inference according to the operation mode schedule.

Database stores the network structure, operation states, apparatus parameters and load data etc. In addition, the knowledge system is also stored in the relational data base.

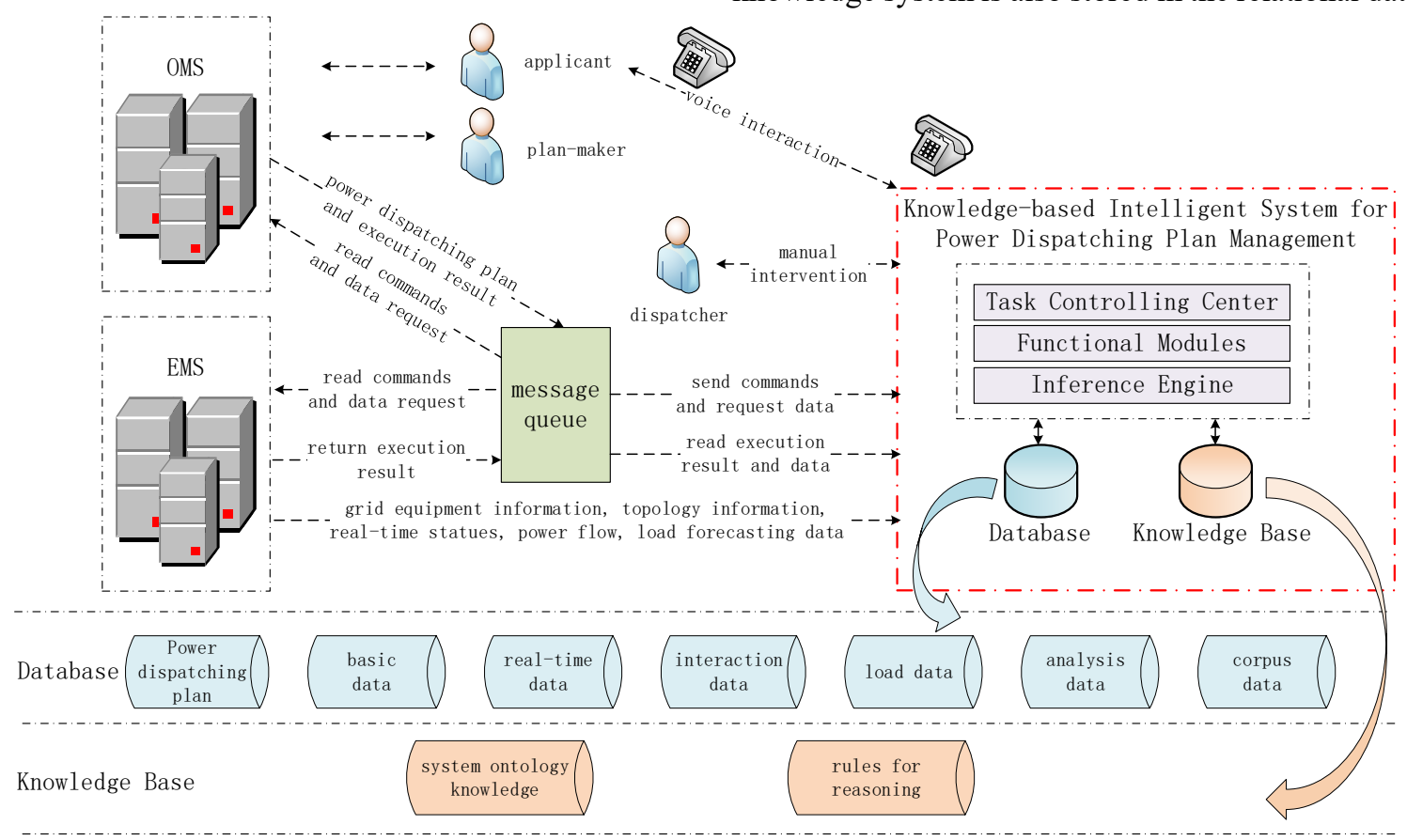

Fig 1. System physical structure.

\subsection{Module functions and technologies}

The functional modules of the IS and the corresponding technologies adopted are shown in Figure 2. We design an integrated natural language understanding (NLU) package to translate the operation mode schedules written in Chinese into computer accessible data forms, where the detail techniques are not introduced in this paper. According to the task information obtained from NLU, the facts about the related power equipment are indexed and transformed into a knowledge expression format that is suitable for computer reasoning.

The PDPM process procedures are decomposed into following functional modules: the associated plan grouping, the security check and dispatching-order ticket generating.

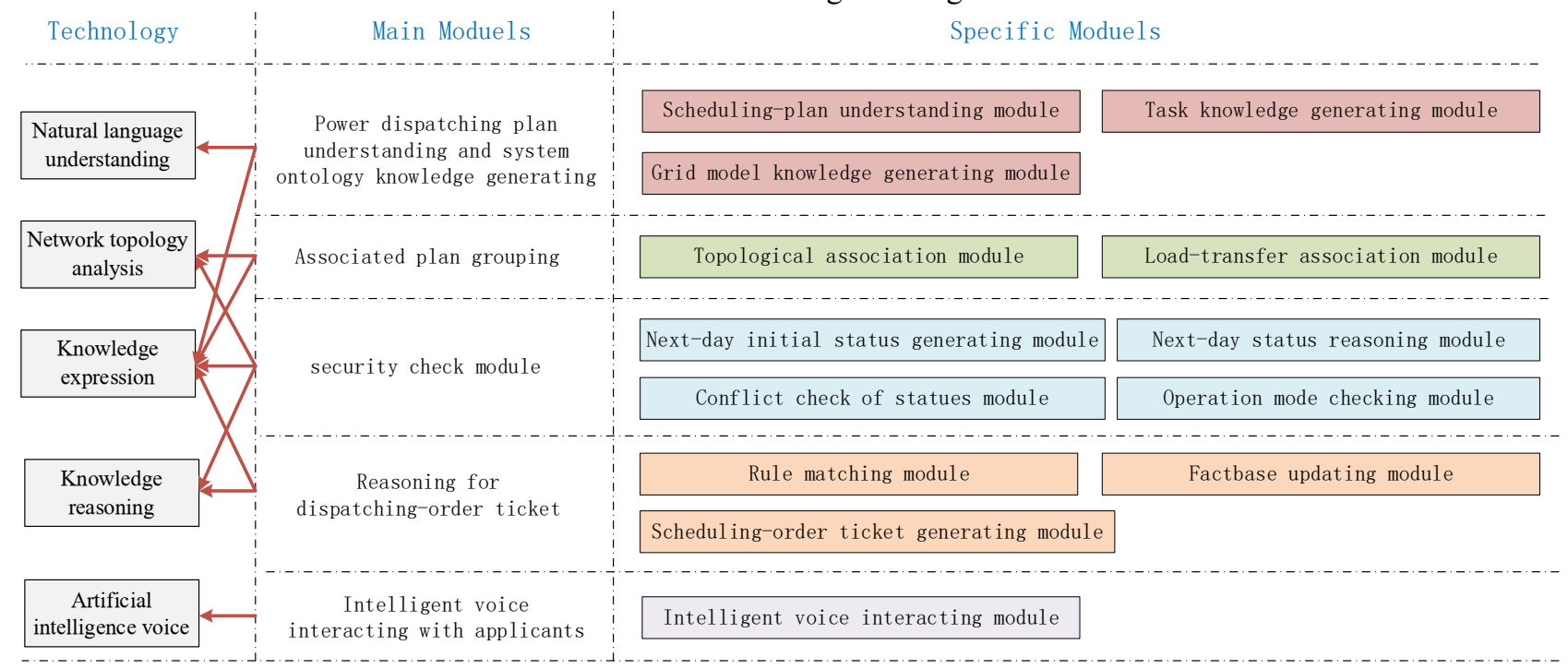

Fig 2. Functional modules corresponding implementation technologies of the system.

The associated plan grouping module (APG) works to identify the correlated plans. Different types of correlation are considered. The first one is the topological association, which means that different plans may have overlapped operating targets with conflicts, such as breakers. The load-transfer association is another factor, for instance, the load is transferred to the same transmission line or transformer in two different power dispatching plans. The 
checking of association covers equipment in different voltage layers from $220 \mathrm{kV}$ to $10 \mathrm{kV}$, while the grid range of interest are obtained according to the plan relevant equipment and the topological information.

The security check module is carried out for each group of plans. At first, the breaker-status time sequences in the next day is generated according to the current operation states and the operation mode schedules. The rule-based reasoning is applied to infer the pre-operation and postoperation breakers and disconnectors statues. And the system will check if the statues of plans in each group have conflicts. Then the operation statues in the next day of each group are divided into 96 time sections (one interval for 15 minutes) with different load levels and operation network topologies. The load flow and load ratios of lines and transformers are calculated to verify the operation limits.

If the plans pass the check, the approved equipment target states will be added to the factbase and the dispatching-order ticket reasoning module will be activated. In this module, the inference engine applies the rule matching algorithm to generate the operation sequences according to the current facts. The designs of the fact and rule expression are introduced in the next section.

\section{Grid knowledge expression based on the first-order logic}

In the proposed IS, we adopt the first-order logic language for knowledge expression as shown in Figure 3. First-order logic can define the relationship for part objects or the whole domain which reduces the number of rules and simplifies the reason process. Here, all the knowledge about the power grid are divided into two large categories, the system ontology knowledge and the rules for reasoning.

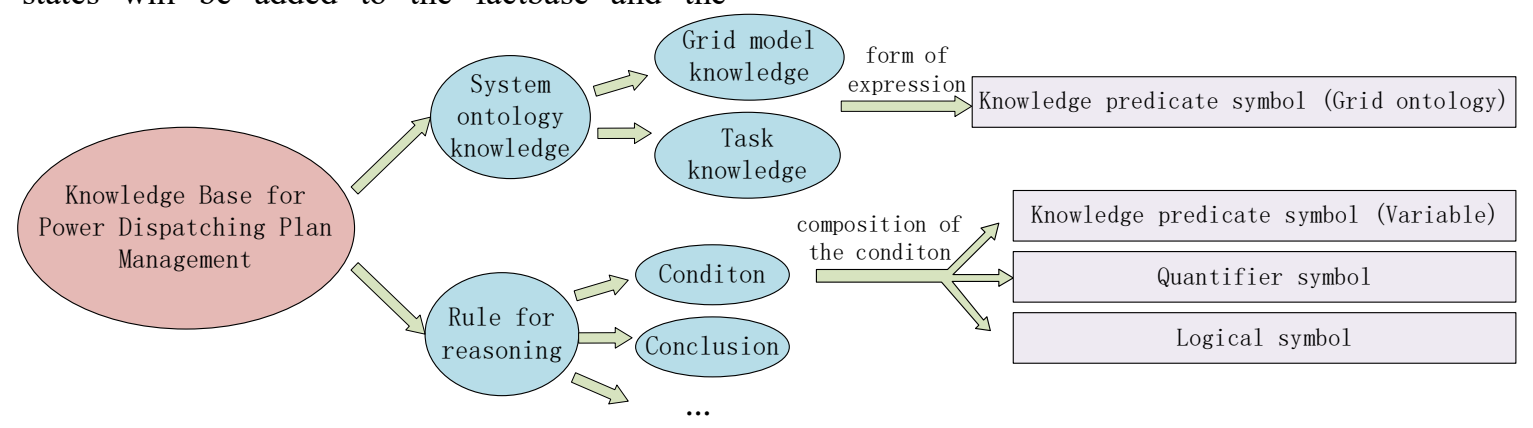

Fig 3. The division and composition of the system knowledge base.

The system ontology knowledge describes the grid equipment related information, whose expression form is the knowledge predicate symbol with parameters. The grid ontology is the real physical equipment in the grid, including power equipment, controlled devices and management departments etc. The knowledge predicate symbols are defined to represent the attributes, relationships and operation tasks of the power system. For example, the predicate symbol 'Transformer (A)' means that $\mathrm{A}$ is a transformer.

The rule for reasoning is composed of premise and conclusion. The premise is consisted of the knowledge predicate symbols, variables, quantifiers and logical symbols in first-order logic form, which shows strong description ability and versatility.

\subsection{The establishment and expression of system ontology knowledge}

We design a hierarchical classification framework for the system ontology knowledge. The ontology knowledge is further divided into two categories. One is the task knowledge obtained from the content of the power dispatching plan through the NLU module, which describes the power outage equipment and operation arrangements. The other is the grid model knowledge, derived from the database.

\subsubsection{Grid model knowledge}

The grid model knowledge includes the static conceptual knowledge, the dynamic conceptual knowledge and the object relation knowledge. The framework is shown in Figure 4, where the knowledge predicates uses the red fonts.

Static conceptual knowledge represents relatively fixed knowledge about the grid, such as the type of equipment, the type of work unit, the mode of bus connection and the target state of the relevant equipment, etc. The target state of equipment describes the state of equipment during the maintenance task.

The dynamic conceptual knowledge describes the dynamic information of the grid ontologies, including the real-time statues of the equipment, the power flow data, etc. They are updated through a data interface with the EMS.

Object relation knowledge represents the topological connection and affiliation of different elements. The affiliation defines the substation and voltage levels of equipment. The switchable equipment includes breaker, disconnector and the grounding switch. 


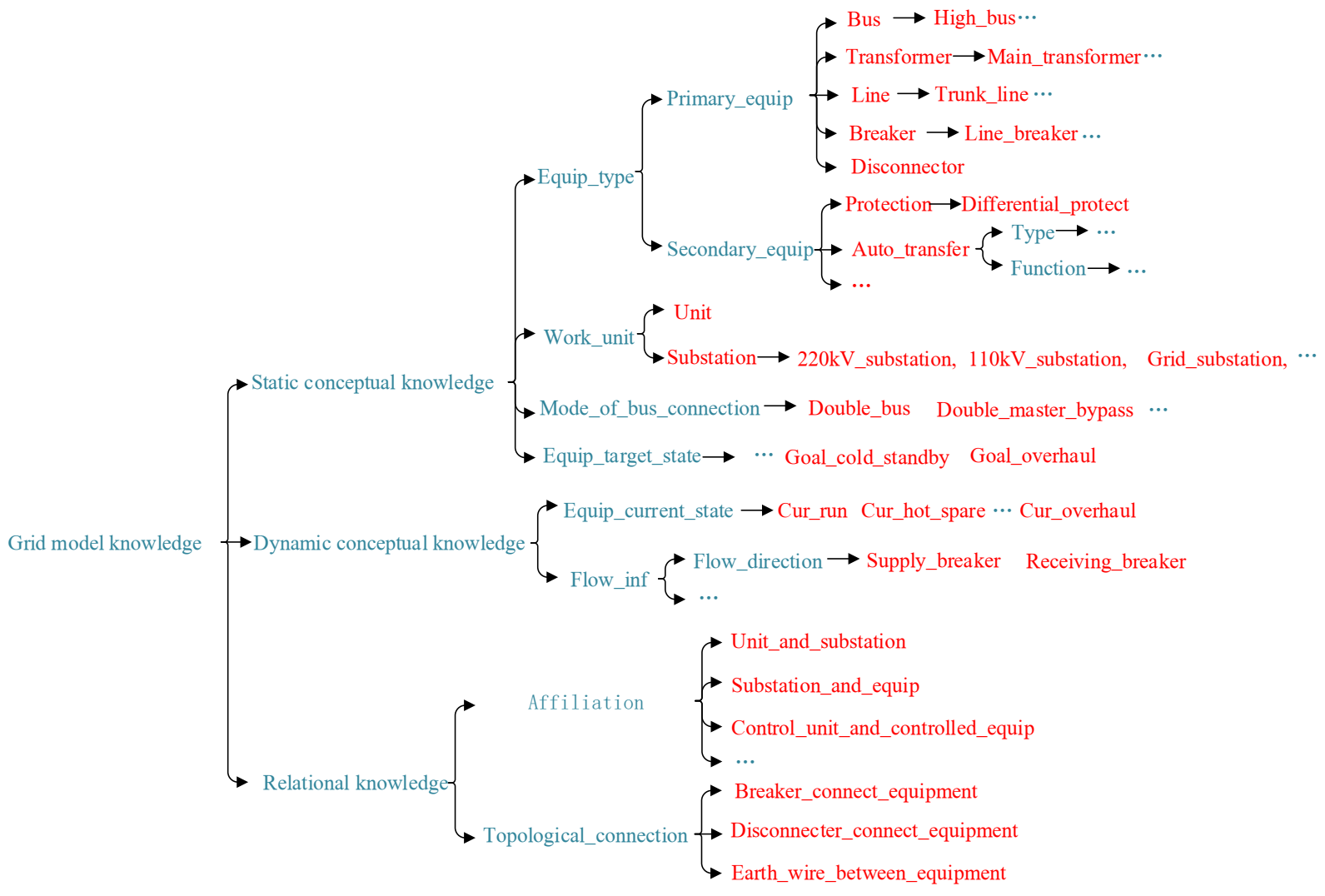

Fig 4. The organization and expression framework of Grid Model Knowledge.

\subsubsection{Task knowledge}

As shown in Figure 5, Task knowledge includes power outage equipment, state confirming tasks and operation tasks which describe different aspects of the plan. The state confirming tasks check the state of equipment in the kernel stage of operation, which are seldom reflected in the dispatching-order tickets. The operation tasks include load transfer, change of bus operation mode, etc. It describes the changes of the power system operation states or controlled equipment.

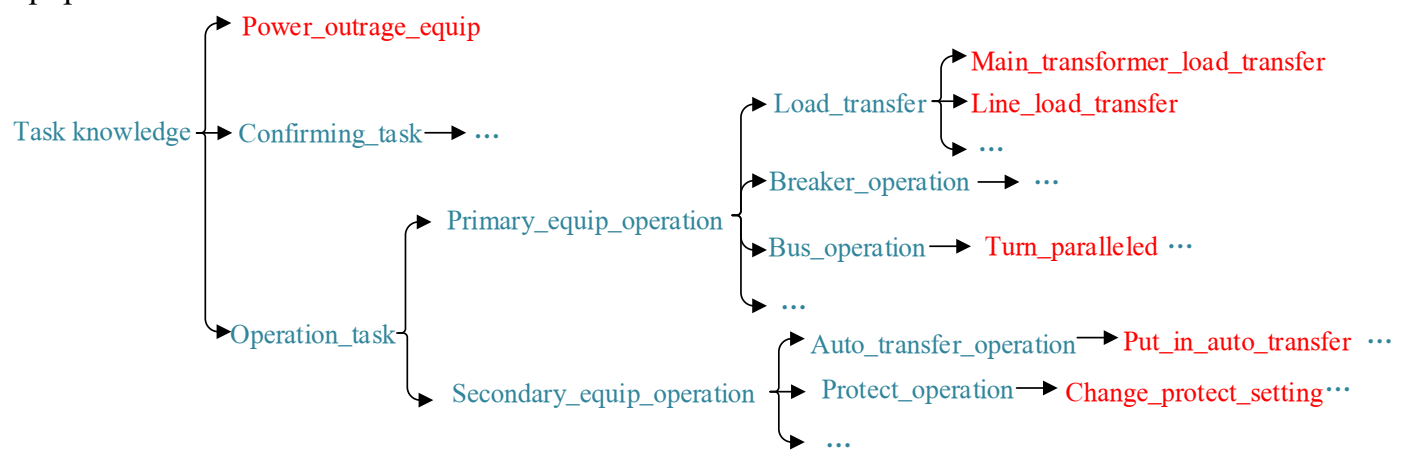

Fig 5. The organization and expression framework of Task Knowledge.

\subsection{Design of rules for reasoning}

The rule for reasoning adopts an enhanced IF-THEN expression as follows:

If: $\mathrm{C}_{\mathrm{d}}$, Then: $\left(\mathrm{C}_{\mathrm{n}}, \mathrm{O}_{\mathrm{p}}, \mathrm{S}_{\mathrm{c}}\right)$, For: $\mathrm{R}_{\mathrm{e}}$, Priority: $\mathrm{P}$ knowledge proposed in this paper organizes the knowledge about the scheduled plan contents, grid topology, power flow information and equipment statues etc. into forms and groups that is easy for analysis and computer reasoning. The knowledge predicate symbols reflect concepts. For example, 'Transformer (B) 'and 'cur_run (B)' mean that the $\mathrm{B}$ is a transformer in operation.

In practical applications, the task knowledge and grid model knowledge related to each plan form the factbase of the plan, which is the source of the knowledge reasoning.
The hierarchical structure of system ontology

$\mathrm{C}_{\mathrm{d}}$ is the rule premise, which is composed of several sub-conditions $\mathrm{C}_{\mathrm{di}}$ and logic symbols such as ' $\&$ ' (and), '|' (or), '!' (not), '->'(contain), '='(equivalence), ' $\forall$ '(fullterm quantifier), ' $\exists$ '(existence quantifier) and so on. The sub-condition $\mathrm{C}_{\mathrm{di}}\left(\mathrm{X}_{\mathrm{i}}, \ldots\right)$ is composed of the knowledge predicate symbol $\mathrm{C}_{\mathrm{di}}$ with variable $\mathrm{X}_{\mathrm{i}}$. 
The rule conclusion consists of three parts: $\mathrm{C}_{\mathrm{n}}\left(\mathrm{X}_{\mathrm{i}}, \ldots\right)$, $\mathrm{O}_{\mathrm{p}}\left(\mathrm{X}_{\mathrm{i}}, \ldots\right)$ and $\mathrm{S}_{\mathrm{c}}\left(\mathrm{X}_{\mathrm{i}}, \ldots\right)$.

$\mathrm{C}_{\mathrm{n}}\left(\mathrm{X}_{\mathrm{i}}, \ldots\right)$ is usually an operation task and $\left(\mathrm{X}_{\mathrm{i}}, \ldots\right)$ describes the operation targets. $\mathrm{S}_{\mathrm{c}}\left(\mathrm{X}_{\mathrm{i}}, \ldots\right)$ defines the influence of the operation task on the state of the system. A general expression of $\mathrm{S}_{\mathrm{c}}\left(\mathrm{X}_{\mathrm{i}}, \ldots\right)$ is 'State_A $\left(X_{i}, \ldots\right) \rightarrow$ State_B $\left(X_{i}, \ldots\right)$ '. $\mathrm{O}_{p}\left(X_{i}, \ldots\right)$ and $R_{e}$ are in the form of Chinese natural language combined with variables. $\mathrm{O}_{\mathrm{p}}\left(\mathrm{X}_{\mathrm{i}}, \ldots\right)$ is specially designed for the inference of the dispatching-order ticket, which gives the template to describe the operation followed the expression standards. $\mathrm{R}_{\mathrm{e}}$ is designed for the explanation of the rule inference process so that the users can review and check the working mechanism of computer.

P means the priority of rules. In order to improve the reasoning efficiency, the inference engine will prefer to activate the rule with high priority value. There is an example of the rule, which is work for the dispatchingorder ticket reasoning in table 1 , where the Chinese expression components, i.e. $\mathrm{O}_{\mathrm{p}}\left(\mathrm{X}_{\mathrm{i}}, \ldots\right)$ and $\mathrm{R}_{\mathrm{e}}$, are omitted.

Table 1. An example of rules for ticket reasoning.

\begin{tabular}{|c|c|c|c|}
\hline $\mathrm{C}_{\mathrm{d}}$ & $\mathrm{C}_{\mathrm{n}}$ & $\mathrm{S}_{\mathrm{c}}$ & $\mathrm{P}$ \\
\hline 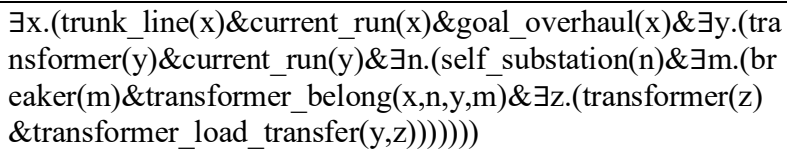 & $\begin{array}{l}\text { execute_transformer } \\
\text { transfer_load(y,z,n } \\
\text {,m) }\end{array}$ & $\begin{array}{l}\text { current_run }(\mathrm{y}) \rightarrow \\
\text { current_cold_standby }(\mathrm{y}), \\
\text { current_run }(\mathrm{m}) \rightarrow \\
\text { current_cold_standby }(\mathrm{m})\end{array}$ & 4 \\
\hline
\end{tabular}

It can be seen from the above table that $\mathrm{C}_{\mathrm{d}}$ involves a large number of variables $\mathrm{X}_{\mathrm{i}}$, which work together to describe complex grid structure, operation mode and equipment relationship, etc. It makes the expression of rules completed, flexible and versatile, which can meet the application requirements of various operation tasks and complex operation modes.

In reason process, the inference engine matches the facts in the factbase with the premise of rules. The system builds in two categories of rules: rules for status reasoning and rules for dispatching-order ticket reasoning.

\section{Case analysis}

In this paper, we use an example to illustrate the functions of the system, where the structure of the corresponding sub-system is shown in Figure 6. The 110kV Line II supplies the $110 \mathrm{kV}$ transformer \#1 in Substation V and the transformer \#1 in Substation W. The $110 \mathrm{kV}$ Line IV supplies transformer \#2 in Substation W. The 110kV bus bar sections of Substation W are supplied by other line separately.

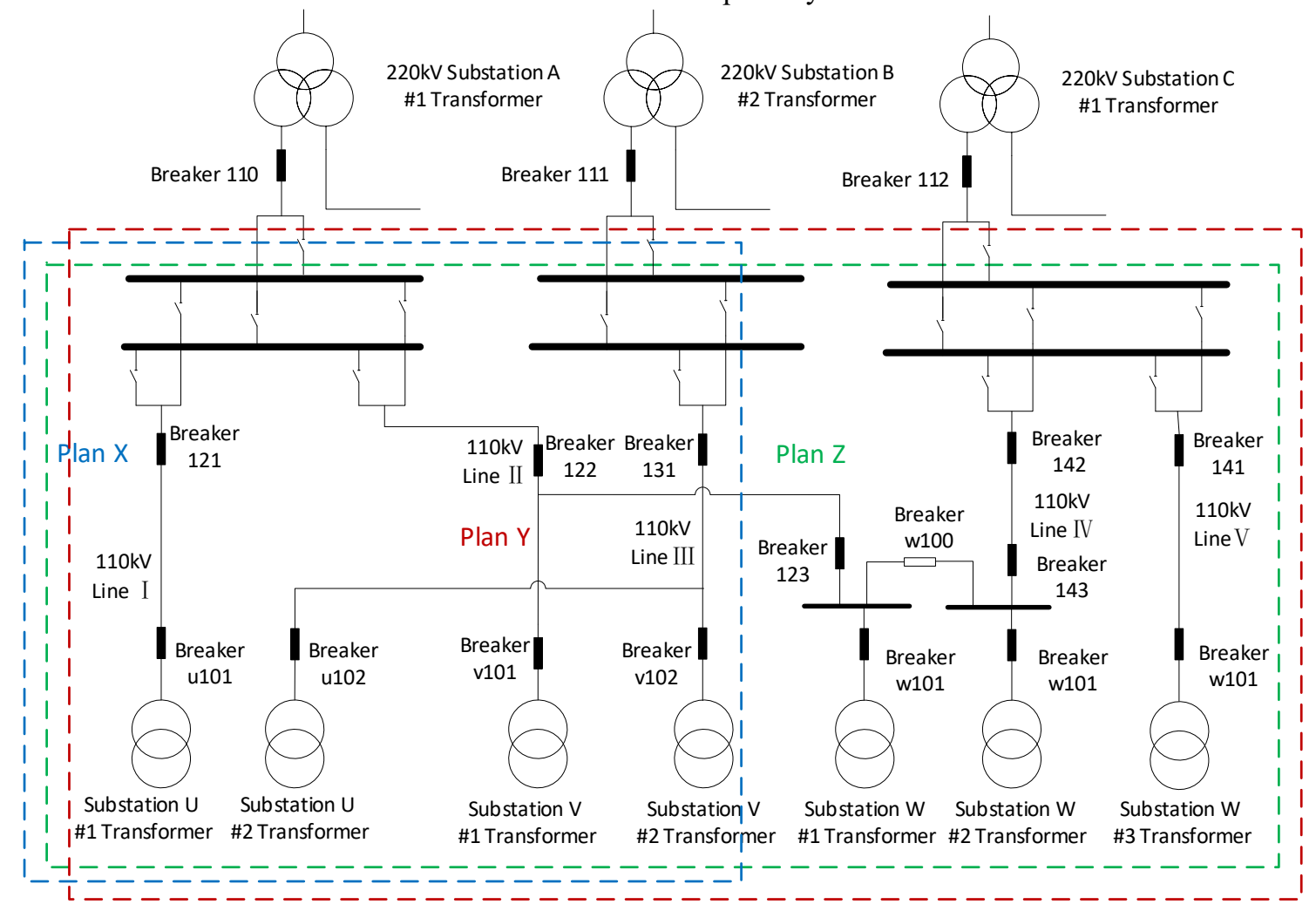

Fig 6. Topology of the case.
The IS received three plans for the next day on the day ahead (September 1st), as shown in Table 2. Technician for the operation mode schedule has submitted their opinion for operation mode changes during the equipment maintenance, which is written in Chinese and has been translated into English in column 3 of table 2. Unless otherwise specified, the operation mode will restore to the same as that before the maintenance. 
Table 2. Examples of power dispatching plan.

\begin{tabular}{|c|c|c|c|c|}
\hline $\begin{array}{l}\text { Plan } \\
\text { Number }\end{array}$ & $\begin{array}{l}\text { Power outage } \\
\text { equipment }\end{array}$ & operation mode schedules & Power outage time & Restoration time \\
\hline $\mathrm{X}$ & $\begin{array}{l}\text { 110kV Line I and } \\
\text { Substation U \#1 } \\
\text { Transformer }\end{array}$ & $\begin{array}{l}\text { Transfer the load of Substation U\#1 } \\
\text { Transformer to \#2 transformer }\end{array}$ & September 2nd 8:00 & $\begin{array}{c}\text { September } 2 \text { nd } \\
18: 00\end{array}$ \\
\hline $\mathrm{Y}$ & $\begin{array}{l}110 \mathrm{kV} \text { Line I and } \\
\text { Substation V \#1 } \\
\text { Transformer }\end{array}$ & $\begin{array}{l}\text { Transfer the load of Substation V\#1 } \\
\text { Transformer to \#2 Transformer. Turn } 110 \mathrm{kV} \\
\text { bus in Substation V into parallel operation }\end{array}$ & September 2nd 9:00 & $\begin{array}{c}\text { September } 2 \text { nd } \\
20: 00\end{array}$ \\
\hline $\mathrm{Z}$ & $\begin{array}{l}\text { Substation W \#3 } \\
\text { Transformer }\end{array}$ & $\begin{array}{l}\text { Transfer the load of Substation W \#3 } \\
\text { Transformer to \#2 Transformer }\end{array}$ & $\begin{array}{c}\text { September } 2 \text { nd } \\
11: 00\end{array}$ & $\begin{array}{c}\text { September } 2 \text { nd } \\
16: 00\end{array}$ \\
\hline
\end{tabular}

The system performs natural language understanding on each plan and then generates the task knowledge. After determining the range of interest in each plan according to the operation mode schedules (as shown by the dotted line in Figure 6), the IS generates the knowledge of the grid model. The task knowledge and grid model knowledge of each plan form its factbase.
Then the three plans are classified into one group since their interest ranges are overlapped. Plan X and $\mathrm{Y}$ are both related to $220 \mathrm{kV}$ Substation A and $220 \mathrm{kV}$ Substation B, and plan $\mathrm{Y}$ and $\mathrm{Z}$ are also both related to the $220 \mathrm{kV}$ Substation C. The grouping results from the associated power dispatching plan module are as following table 3 .

Table 3. Grouping results of associated power dispatching plans.

\begin{tabular}{l}
\hline \multicolumn{2}{c}{ Association group } \\
\hline Power dispatching plan $\mathrm{X}, \mathrm{Y}, \mathrm{Z}$ \\
\hline
\end{tabular}

After the table of next-day initial statues of breakers and disconnectors is formed, the reasoning for next-day statues is performed for each plan in the group. The system matches the facts in the factbase with the status reasoning rules. Some of the results are shown in Table 4, where the disconnectors statues are omitted for simplification and $0 / 1$ refers to the breaker states of opened/closed.

Table 4. The breaker statues of each plan.

\begin{tabular}{|c|c|c|c|}
\hline Plan number & Pre-operation breaker statues & \multicolumn{2}{|c|}{ Breaker operation statues } \\
\hline \multirow{2}{*}{$\mathrm{X}$} & \multirow{2}{*}{$121-1$, u101-1, u102-1 } & $8: 00-18: 00$ & $121-0$, u101-0, u102-1 \\
\hline & & 18:00-24:00 & 121-1, u101-1, u102-1 \\
\hline \multirow{2}{*}{ Y } & \multirow{2}{*}{$\begin{array}{l}\begin{array}{ll}122-1, & \mathrm{v} 101-1, \\
\mathrm{w} 100-0, & \ldots\end{array}\end{array}$} & 9:00-20:00 & $122-0$, v101-0, v102-1, $\ldots$ \\
\hline & & 20:00-24:00 & $122-1, \mathrm{v} 101-1, \mathrm{v} 102-1, \ldots$ \\
\hline Z & 141-1, w103-1, .. & $11: 00-24: 00$ & $141-0$, w103-0, ... \\
\hline
\end{tabular}

According to the inferred breaker statues, the system performs the check of breaker statues in each power dispatching plan:

(1) The system checks the pre-operation statues of each plan with the next-day initial statues table. If the statues are consistent, it will be proved that there is no conflict between the grid operation mode schedules of each power dispatching plan with the grid statues.

(2) The system performs conflict detection on the breaker operation statues of multiple power dispatching plans in the association group. Since there is no operation status of the same breaker in power dispatching plans in the group, it is confirmed that the operation mode contradiction does not exist among the power dispatching plans. Therefore, the correctness of each plan's operation mode is verified.

Then the next day's all-day breaker-statues in the group is divided by the interval of 15 minutes, as shown in the following table 5 .

Table 5. Next day's all-day breaker-statues of the association group.

\begin{tabular}{ll}
\hline Time & Breaker statues \\
\hline $8: 00$ & $121-0, \mathrm{u} 101-0, \mathrm{u} 102-1,122-1, \mathrm{v} 101-1, \mathrm{v} 102-1, \ldots$ \\
$\ldots$ & $\ldots$ \\
$9: 00$ & $121-0, \mathrm{u} 101-0, \mathrm{u} 102-1,122-0, \mathrm{v} 101-0, \mathrm{v} 102-1, \ldots$ \\
$\ldots$ & $\ldots$ \\
$18: 00$ & $121-1, \mathrm{u} 101-1, \mathrm{u} 102-1,122-0, \mathrm{v} 101-0, \mathrm{v} 102-1, \ldots$ \\
$\ldots$ & $\ldots$
\end{tabular}


All 220kV grid partitions corresponding to plan X, Y and $\mathrm{Z}$ are taken as the topological range to be calculated. The table of the next-day initial statues of breakers and disconnectors is read as the initial statues in the calculation range. Calculation and judgment are performed according to the breaker statues of each state section and the loadforecast data of the equipment that is called in real time. The unqualified results in the calculation results are as table 6.

Table 6. Overload results of the association group.

\begin{tabular}{ccccc}
\hline Overload Time & Overload Equipment & $\begin{array}{c}\text { Overload } \\
\text { Numerical Value }\end{array}$ & Load of Related equipment & $\begin{array}{c}\text { Related power } \\
\text { dispatching } \\
\text { plans }\end{array}$ \\
\hline $12: 15$ & $110 \mathrm{kV}$ Line III & $0.56 \mathrm{kA}$ & $\begin{array}{c}\text { Substation U \#2 transformer: 2.12kA; } \\
\text { Substation V \#2 transformer: 2.45kA }\end{array}$ & X, Y \\
\hline
\end{tabular}

Based on above inference, the system sends back plan $\mathrm{X}$ and $\mathrm{Y}$ to the department for operation mode arrangement with suggestion that arrangement for the $10 \mathrm{kV}$ bus transfer should be added. Only after revision, these two plans can be re-approved.

Since there is no overload on the Main transformer \#2 in Substation $\mathrm{W}$, the operation mode check of plan $\mathrm{Z}$ will pass. After obtaining the equipment target states of plan $\mathrm{Z}$, the IS performs the reasoning of the dispatching-order ticket. For the outage of the \#3 main transformer in Substation $\mathrm{W}$, the result is shown in the following table 7 .

Table 7. Dispatching-order ticket of plan Z.

\begin{tabular}{|c|c|c|c|}
\hline Sequence & $\begin{array}{l}\text { Operation } \\
\text { sequence }\end{array}$ & Substation & Dispatching order \\
\hline 1 & 1 & Substation W & Transfer the load of \#3 Transformer to \#2 Transformer \\
\hline 2 & 1 & Substation C & Confirm 110kV Line V has the dispatching operation conditions \\
\hline 3 & 2 & Substation $\mathrm{C}$ & Disconnect the Breaker 141 on the $110 \mathrm{kV}$ Line $\mathrm{V}$ by remote controlling \\
\hline 4 & 3 & Substation C & $\begin{array}{l}\text { Turn the state of Breaker } 141 \text { on the } 110 \mathrm{kV} \text { Line V from hot spare to cold } \\
\text { standby }\end{array}$ \\
\hline 5 & 4 & Substation $\mathrm{C}$ & Turn the state of $110 \mathrm{kV}$ Line $\mathrm{V}$ from cold standby to overhaul \\
\hline
\end{tabular}

The above analysis example verifies the function and effectiveness of the dispatching plan intelligent processing system proposed in this paper. The system is now on the field test and the total process for day-ahead management is fast and reliable, which greatly improves the efficiency of the work.

\section{Conclusion}

This paper proposes a knowledge based intelligent system for day-ahead power dispatching plan processing and decision making, which can replace the human dispatcher in the corresponding work. The paper focuses on the design of knowledge expression and the module construction of the system. An example is given to verify the effectiveness of the proposed scheme.

The research work is supported by the Guangzhou Power Supply Co. of China under Grant no. GZHKJXM20170059.

\section{References}

1 C. Darab, R. Tarnovan, A. Turcu and C. Martineac.Artificial Intelligence Techniques for Fault Location and Detection in Distributed Generation Power Systems. In: 2019 8th International Conference on Modern Power Systems (MPS), 2019: 1-4.

2 L. Wu, J. Gao, G. K. Venayagamoorthy and R. G. Harley. On Artificial Intelligence Approaches for Contingency Analysis in Power System Security
Assessment. In:2018 IEEE Power \& Energy Society General Meeting (PESGM), 2018:1-5.

3 C. Tong, Y. Cai, Z. Zhang, Q. Wang, Y. Gao, J. Li, et al.. Artificial intelligence-based lightning protection of smart grid distribution system. In:2017 International Symposium on Lightning Protection (XIV SIPDA), 2017: 279-286.

$4 \mathrm{H} . \mathrm{Xu}, \mathrm{J}$. $\mathrm{Lu}$ and Z.Yang. CiteSpace Based Knowledge Mapping Research of Artificial Intelligence Technology in Power System. In:2018 International Conference on Power System Technology (POWERCON), 2018:4383-4389.

5 A. Purwar, D. Joshi and M. S. Dasgupta. Smart control of electric lamp using artificial intelligence based controller. In:2015 Annual IEEE India Conference (INDICON), 2015: 1-5.

6 E. O. Kontis, T. A. Papadopoulos, M. H. Syed, E. Guillo-Sansano, G. M. Burt and G. K. Papagiannis.Artificial-Intelligence Method for the Derivation of Generic Aggregated Dynamic Equivalent Models. IEEE Transactions on Power Systems, 2019; 34(4):2947-2956.

7 S. Chen. Dispatching operation sheet system of power network based on multi-agent system. In: Proceedings of 2011 International Conference on Electronic \& Mechanical Engineering and Information Technology, 2011:3754-3757.

8 J. Liu, Y. Wang, M. Lu, P. Xu, F. Lil and J. Geng. A Practical Approach to Generating Trend Data of Power Grid Operation for Pre-dispatching System. In: 
2018 2nd IEEE Conference on Energy Internet and Energy System Integration (EI2), 2018: 1-4.

9 SHAN Xin, LU Xiao, ZHAI Mingyu, et al.. Analysis of Key Technologies for Artificial Intelligence Applied to Power Grid Dispatch and Control. Automation of Electric Power Systems, 2019; 43(1):49-57.
10 ZHANG Xiaohua, FENG Changyou, WANG Yongming, et al.. Design Ideas of Robotic Dispatcher for Power Grid. Automation of Electric Power Systems, 2019; 43(13):1-8.

11 J. J. Zhang, F.Wang, Q Wang, D. Hao, X. Yang, D.W.Gao et al.. Parallel dispatch: a new paradigm of electrical power system dispatch, IEEE/CAA Journal of Automatica Sinica, 2018; 5(1):311-319. 